九州大学学術情報リポジトリ

Kyushu University Institutional Repository

Taxonomic Notes on the Apristum Species Group Belonging to the Subgenus Evylaeus of the Genus Lasioglossum with Redescription of Two Species (Hymenoptera: Halictidae)

Murao, Ryuki

Tadauchi, Osamu

https://doi.org/10.5109/2701

出版情報: ESAKIA. 45，pp.41-54，2005-03-31. Entomological Laboratory，Faculty of Agriculture， Kyushu University

バージョン：

権利関係 : 
ESAKIA, (45): 41-54. March 31, 2005

\title{
Taxonomic Notes on the Apristum Species Group Belonging to the Subgemus Evylaeus of the Gemus Lasioglossum with Redescription of Two Species (Hymenoptera: Halictidae) ${ }^{1)}$
}

\author{
Ryuki MuraO \\ Entomological Laboratory, Graduate School of Bioresource and Bioenvironmental Sciences, \\ Kyushu University, Fukuoka, 812-8581 Japan \\ and \\ Osamu TADAUchi \\ Entomological Laboratory, Faculty of Agriculture, Kyushu University, \\ Fukuoka, 812-8581 Japan
}

\begin{abstract}
The apristum species group belonging to the subgenus Evylaeus of the genus Lasioglossum is treated. Two species of this species group, Lasioglossum apristum (Vachal) and Lasioglossum serratum (Blüthgen) are redescribed with illustrations of important characters. Remarks, geographical distribution, flight records and floral associations for each species are presented. We propose a definition of the apristum species group.

Key words: taxonomy, Hymenoptera, Halictidae, Lasioglossum, Evylaeus, apristum species group.
\end{abstract}

\section{Introduction}

The subgenus Evylaeus belongs to the series Hemihalictus of the genus Lasioglossum of the subfamily Halictinae, whose members are known to occur from the Holarctic Region (Michener, 2000). In the Palaearctic Region, this subgenus mainly divided into two groups (carinate-Evylaeus group and carinaless-Evylaeus group) based on the adult morphology. These two groups contain many species groups.

The apristum species group belongs to the carinate-Evylaeus group, and contains seven spe-

1) Contribution from the Entomological Laboratory, Faculty of Agriculture, Kyushu University, Fukuoka (Ser. 6, No. 10). 
cies in the Palearctic Region (Ebmer, 2002) as follows: Lasioglossum apristum (Vachal), L. elaiochromon (Ebmer), L. laeve (Kirby), L. rubsectum (Fan \& Ebmer), L. salebrosum (Blüthgen), L. serratum (Blüthgen), and L. subrubsectum (Fan \& Ebmer). Lasioglossum laeve and L. salebrosum tentatively belong to this species group by Ebmer. As Ebmer (2002) did not present the definition of this species group, we redescribe L. apristum and L. serratum which are available in the present study, and propose a definition of the apristum species group.

\section{Material and Methods}

The specimens examined in this study were borrowed from the following institutions and personal collection, which are referred to in the text by the following abbreviations. $\mathbb{E L K U}$ : Entomological Laboratory, Faculty of Agriculture, Kyushu University, Fukuoka Pref., Japan; SCMH: Late Dr. S. F. Sakagami's Collection, Museum of Nature and Human Activities, Hyogo Pref., Japan; ALKK: Applied Entomological Laboratory, Kyushu Tokai University, Kumamoto Pref., Japan. Other specimens without abbreviation belong to private collection, which is temporarily kept at the Entomological Laboratory, Kyushu University, Fukuoka, Japan.

The morphological terminology in description followed Eickwort (1969), Sakagami and Tadauchi (1995), and Michener (2000). The terms and their abbreviations used are as follows: $\mathbb{B L}$ (body length) : Measured from the base of antennal fossae to the apex of pygidial plate; WL (wing length): Measured in a straight line from the base of tegula to the tip of the forewing; HL, HW (head length and width): Length from the top of vertex to lower margin of clypeus excluding clypeal tooth; width from the compound eye at lower level of antennal fossae; $\mathrm{CAL}$ (clypealveolar distance): Distance between level of lower rims of antennal sockets and upper margin of clypeus; $\mathrm{CPL}$ (clypeal length): Measured from the apicomedian margin of the clypeus to the supraclypeal suture; $\mathbb{E W}, \mathbf{G W}$ (eye and genal widths): Eye and genal widths seen laterally, keeping both antennal bases at the same plane; OOD (ocellocular distance): Distance between the lateral ocellus and the inner margin of compound eye at the shortest line; IOD (interocellar distance): Distance between the lateral ocellus; OCD (ocelloccipital distance) : Distance between the lateral ocellus and the vertex; UOD: Upper interocular distance; MOD: Maximum interocular distance; LOD: Lower interocular distance; SPL: Scape length; $\mathbb{F} \boldsymbol{n}$ : Flageller segment number $n ; \mathbb{F} \boldsymbol{n L}$ : Length of flageller segment number $n ; \mathbf{M s W}$ (mesosomal width): Width between the outer rim of tegulae; MtW: Metasomal width (width in maximal metasomal tergum); MCL: Length of scutellum; MTL: Length of metanotum; PDL: Length of propodeum dorsum; $\mathbf{T} n, \mathbf{S} n$ : Segment number $n$ of metasomal tergum and sternum; PP: Punctures; IS: Interspace of punctures; Flight records: indicates collecting month of the adults; Floral association: indicates flowering plants on which bees were collected. 


\section{The apristum species group Ebmer}

Lasioglossum apristum species group Ebmer, 2002, Linzer Biol. Beitr., 34: 839.

This species group is characterized by having the following morphological features: head and mesosoma weakly blue-green reflections in female; distal process of labrum spoon-shaped in female; inner hind tibial spur serrate in female; gonocoxites with inner margin hoe-shaped anteriorly.

\section{Lasioglossum (Evylaeus) apristum (Vachal)}

(Figs. 1 A-G; 2 A-G; 3 A-B; 4 A-D)

Halictus apristus Vachal, 1903, Bull. Mus. Hist. Nat.: 130 [female, Japan]; Hirashima, 1957, Sci. Bull. Fac. Agr., Kyushu Univ., 16 (1): 4.

Sphecodes pallidulus Matsumura, 1912, Thous. Ins. Jap., Suppl. IV: 209-210 [female];

Matsumura, 1930, Illustr. Thous. Ins. Jap. II: 178; Matsumura, 1931, 6000 Illustr. Ins. Jap.-Emp.: 9; Matsumura, 1932, Illustr. Comm. Ins. Jap. IV: 7, 11.

Lasioglossum (Evylaeus) pallidulum: Sakagami \& Munakata, 1966, J. Kansas Entomol. Soc. 39: 370-379 [biology].

Lasioglossum (Evylaeus) apristum: Ebmer, 1978, Annls. Hist. Nat. Mus. Natn. Hung., 70: 313-314; Ebmer, 1995, Linzer biol. Beitr., 27 (2) : 542-544 [male]; Miyanaga et al., 1999, Insectes Soc., 46: 224-232 [biology]; Ikudome, 1999, Ident. Guide Aculeata Nansei Is., Jap.: 582; Ebmer, 2002, Linzer. biol. Beitr., 34 (2) : 840-841.

\section{Redescription}

Femalle. BL 7.10-8.90 mm, WL 6.20-7.40 mm ( $\mathrm{n}=5)$.

Color: Body black except as follows: mandible with apical half reddish brown; flagellum beneath blackish brown; tegula posteriorly and marginally brownish transparent; wings nearly transparent; veins and pterostigma brown; tibial spur yellow; posterior margins of metasomal terga broadly brownish yellow transparent.

Pilosity: Generally dull whitish to pale yellowish brown. Head: Hairs on vertex 100-150 $\mu \mathrm{m}$, erect and poorly plumose, sparse; hairs on paraocular area, frons and supraclypeal area 80-180 $\mu \mathrm{m}$, poorly plumose, sparse; hairs on clypeus $80-250 \mu \mathrm{m}$, simple, moderately dense; hairs on genal area 100-300 $\mu \mathrm{m}$, poorly plumose, moderately dense, below admixture with simple. Mesosoma: Lateral lobe of pronotum with tomental hairs; hairs on pronotal dorsum, plumose, moderately dense; hairs on mesoscutum 60-140 $\mu \mathrm{m}$, marginally semierect and poorly plumose, moderately dense, medially simple short, and sparse; hairs on mesoscutellum 


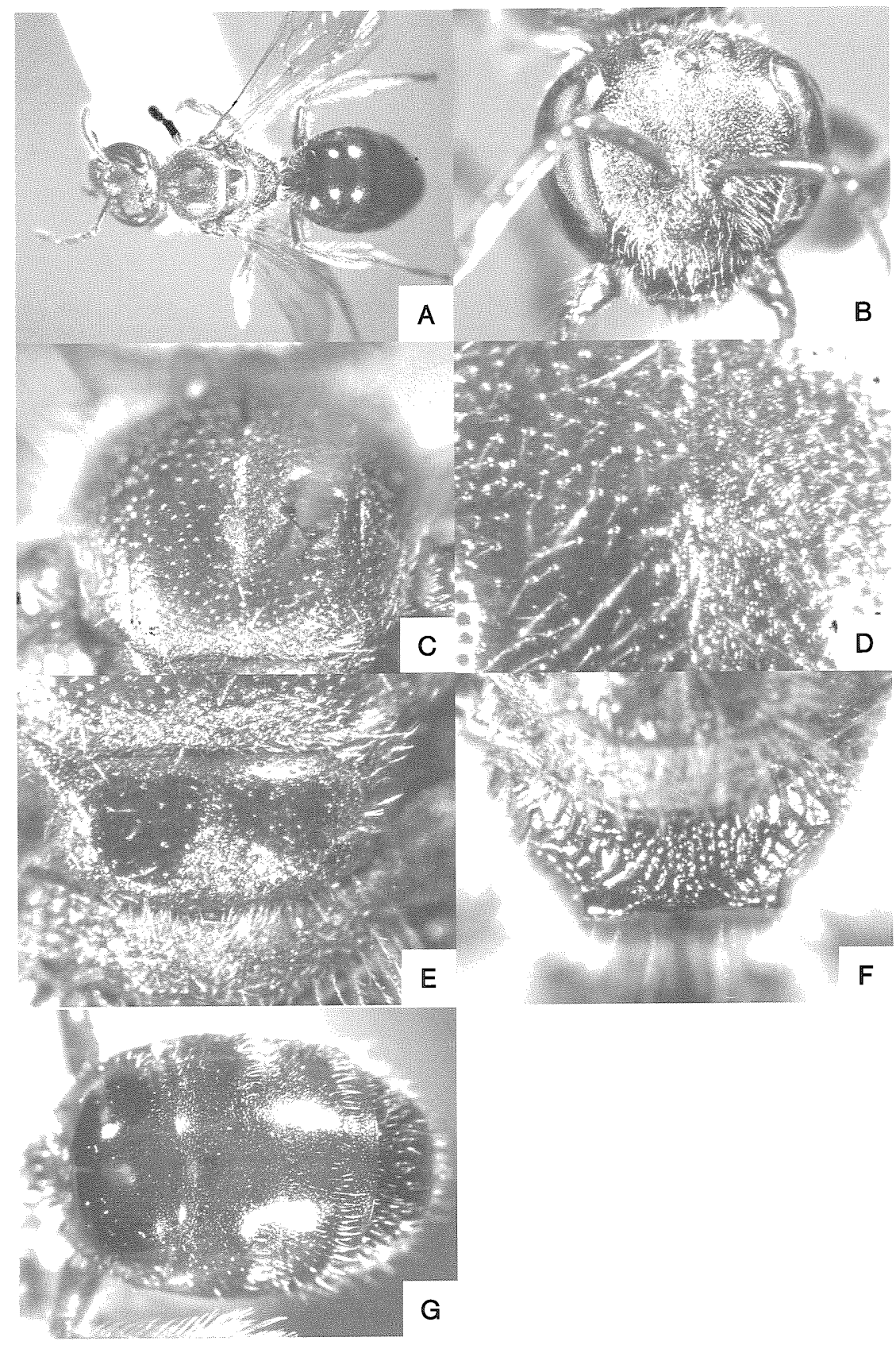

Fig. 1. Lasioglossum (Evylaeus) apristum (Vachal), female. A: dorsal view; B: face; C: mesoscutum; D: sculpture of mesoscutum; E: mesoscutellum; F: propodeal dorsum; G: metasomal terga. 


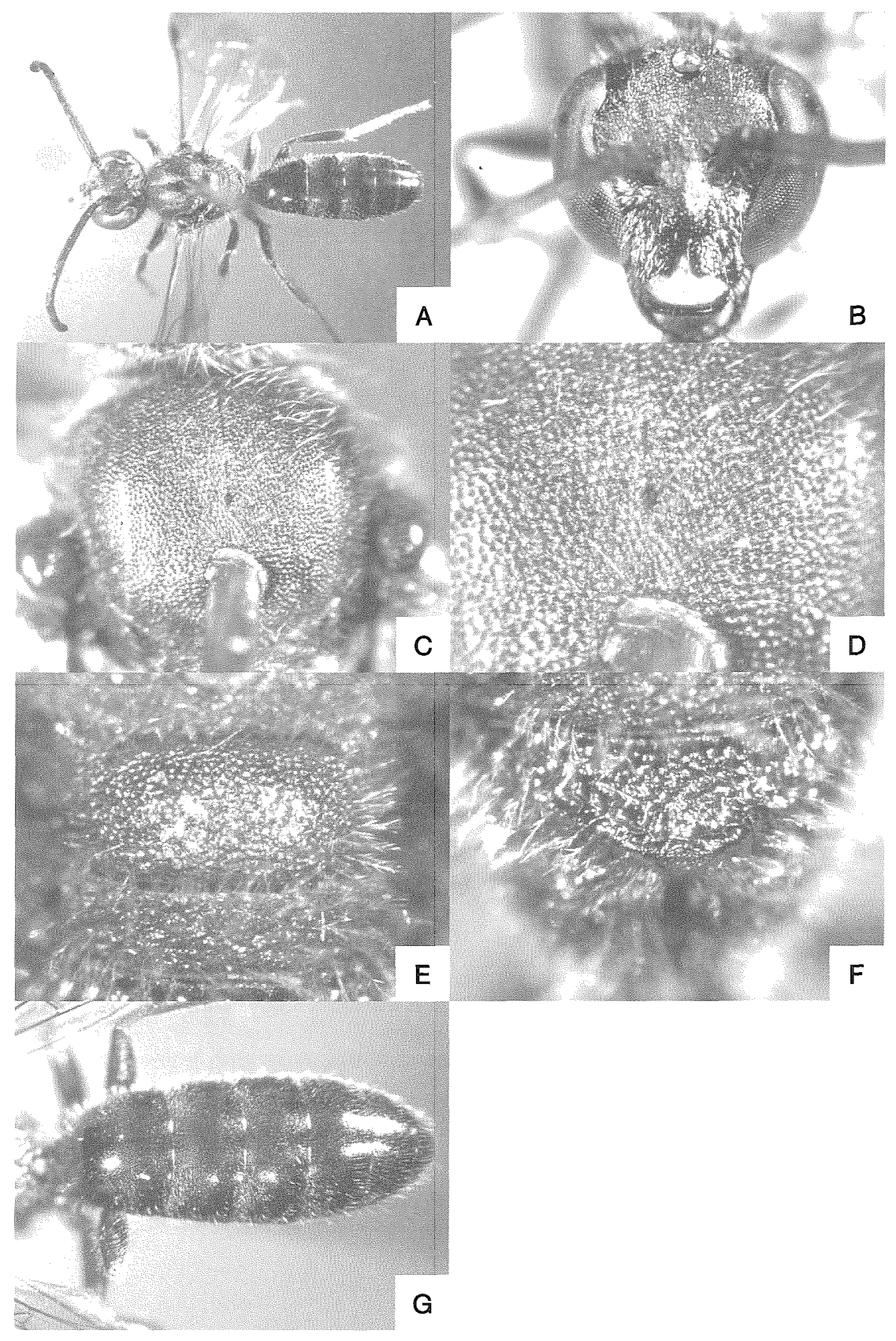

Fig. 2. Lasioglossum (Evylaeus) apristum (Vachal), male. A: dorsal view; B: face; C: mesoscutum; D: sculpture of mesoscutum; E: mesoscutellum; F: propodeal dorsum; G: metasomal terga. 
100-300 $\mu \mathrm{m}$, marginally plumose, sparse; hairs on metanotum medially tomentum, dense, marginally plumose, sparse; tegula with poorly plumose hairs anteriorly; hairs on mesepisternum and metepisternum 100-400 $\mu \mathrm{m}$, plumose, moderately dense; hairs on propodeal side plumose, moderately dense, and admixture with simple; hairs on propodeal shield plumose, sparse. Metasoma: Hairs pale yellowish brown; anterior and lateral hairs of T1 $80-160 \mu \mathrm{m}$, erect and poorly plumose, sparse; hairs on T2 simple and short, sparse, laterally poorly plumose; hairs on T3-4 simple and short all over, laterally admixture with a few of poorly plumose; basal hair bands of T2-4 present (sometimes obscure) with whitish tomentum; hairs on metasomal sterna $300-600 \mu \mathrm{m}$, simple, moderately dense and admixture with a few of poorly plumose.

Structure: Head: HW: HL= 2.09: 1.94. Vertex gently outcurved in frontal view, behind ocelli with rugulose; IOD: $\mathrm{OOD}: \mathrm{OCD}=0.31: 0.30: 0.07$. Ocellocular and paraocullar areas weakly shiny, with reticulo-punctures $(20-30 \mu \varnothing)$; frons nearly flat, dull, with homogenous $\mathrm{PP}$, similar to ocellocular and paraocular areas. $\mathrm{CAL}: \mathrm{CPL}=0.54: 0.45$. Supraclypeal area slightly convex in lateral view, with granular PP (20-30 $\mu \varnothing)$, sparse, IS $=1-4$, weakly reticulate. Clypeus nearly flat, weakly shiny, with larger shallow PP (20-40 $\mu \varnothing)$, sparse, weakly reticulate above, smooth below. UOD: MOD: LOD $=1.20: 1.52: 1.19$. Labrum with basal area and distal process; basal area about 2.5 times as wide as long, apically with slightly depressed in dorsal view; basal lateral depression absent; basal elevation well developed, apically narrow; distal process as wide as basal elevation in dorsal view; distal lateral projection present, with spoon-shaped in dorsal view; distal keel narrow, apically pointed in dorsal view; labral fimbria all acutely pointed at apex. Mandible bidentate. Hypostomal carina moderately developed; anterior angle of hypostomal carina obtuse. Occiput not carinate. $\mathrm{EW}: \mathrm{GW}=0.54$ : 0.41 ; genal area shorter than eye, surface with oblique striae; SPL=0.94 -1.00, F1L: F2L $=$ 0.12: 0.12. Mesosoma: $\mathrm{HW}: \mathrm{MsW}: \mathrm{MtW}=2.09: 2.40: 2.50$. Pronotum with dorsolateral angle obtuse. Mesoscutum shiny, medially with granular PP (20-30 $\mu$ ø), sparse, IS=1-5, weakly reticulate, marginally with granular $\mathrm{PP}$, moderately dense, $\mathrm{IS}=0.2-1$, distinctly reticulate; mesoscutellum, nearly flat, shiny, marginally and longitudinally with homogenous PP and IS, similar to mesoscutum; metanotum rugulose. Mesepisternum distinctly transverse to oblique striae all over; metepisternum above half with homogenous striae with mesepisternum; MCL: MTL: PDL $=0.51: 0.35: 0.42$. Propodeal dorsum gently inclined and weakly convex apically in lateral view; dorsal propodeal surface with distinct ridges all over, medially with irregularly winding ridges, laterally with longitudinal ridges attain to lateral slope; transverse carina weak; lateral carina developed, parallel-sided; oblique carina developed, but not connected each other at upper ends; propodeal side rugulose; shield distinctly reticulate, median with longitudinal concave. Tegula reticulate anteriorly, smooth and weakly shiny posteriorly. Hind legs with basitibial plate ovate, pointed apically; inner hind tibial spur serrate. Metasoma: metasomal terga weakly shiny. T1 medially to posteriorly with fine PP $(<10 \mu \emptyset)$, 
sparse, IS smooth; T2 basally to medially with homogenous PP with T1, dense, posteriorly with sparse, IS weakly transverse striae all over; T3-4 similar to T2. Metasomal sterna distinctly reticulate.

Male. BL 6.60-8.30 mm, WL 5.80-6.90 mm ( $\mathrm{n}=5)$.

Color: Body black except as follows: flagellum blackish brown, beneath brown; lower half of clypeus yellow; mandible with apical half reddish brown; tegula posteriorly and marginally brownish transparent; wings nearly transparent; veins and pterostigma blackish brown; mesosoma dull blue-green; all tarsi yellowish brown; tibial spur yellow; posterior margins of metasomal terga narrowly brownish yellow transparent.

Pilosity: Similar to female except as follows: Head: hairs on paraocular area $100-300 \mu \mathrm{m}$, medially plumose, dense, below admixture with appressed plumose; hairs on supraclypeal area and clypeus $60-140 \mu \mathrm{m}$, plumose, and admixture with appressed plumose, moderately dense. Mesosoma: hairs on metanotum 150-300 $\mu \mathrm{m}$, plumose, sparse. Metasoma: hairs on T1 60-140 $\mu \mathrm{m}$, medially simple and short, sparse; hairs on $\mathrm{T} 2-4$, basally to posteriorly with simple and short, moderately dense, laterally with simple and long; hairs on metasomal sterna 100-160

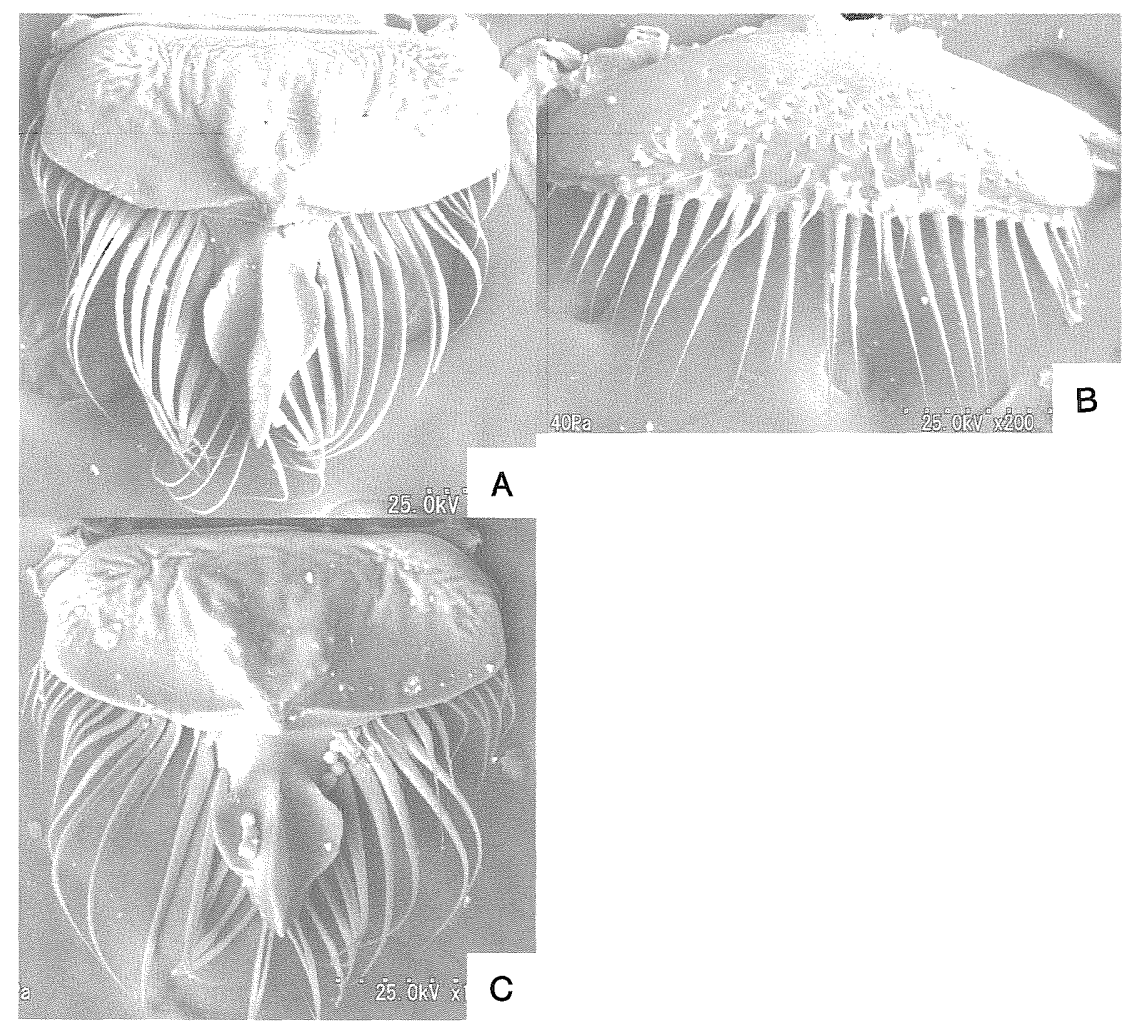

Fig. 3. Labrum. Lasioglossum (Evylaeus) apristum (Vachal), A: female; B: male. Lasioglossum (Evylaeus) serratum (Blüthgen), C: female. 


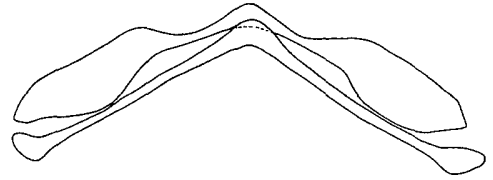

A

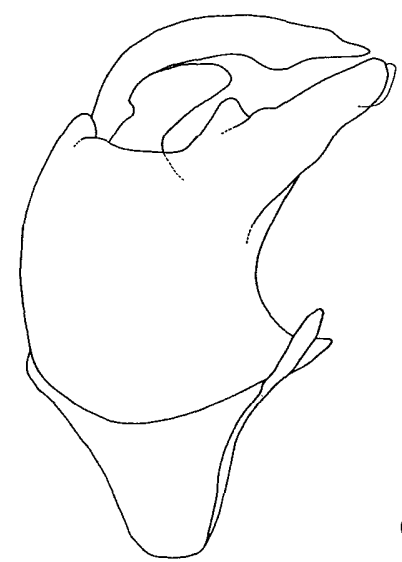

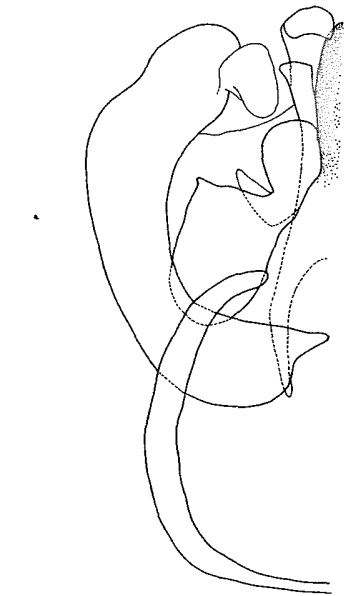

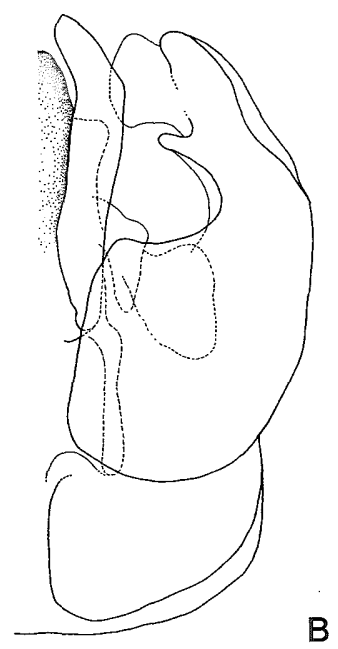

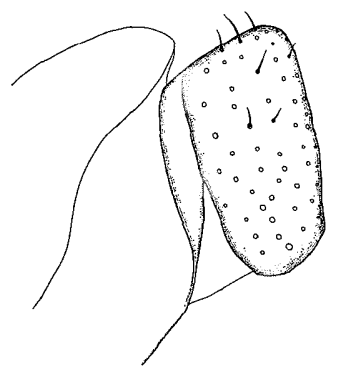

C

Fig. 4. Lasioglossum (Evylaeus) apristum (Vachal), male. A: S7-8; B: genitalia (left, ventral view; right, dorsal view) ; $\mathrm{C}$ : genitalia in lateral view; $\mathrm{D}$ : gonostylus (left, ventral view; right, dorsal view).

$\mu \mathrm{m}$, simple and short, sparse; basal hair bands absent.

Structure: Female except as follows: Head: HW: HL= 1.93: 1.89. Vertex medially weakly depressed in frontal view; IOD: $\mathrm{OOD}: \mathrm{OCD}=0.37: 0.26: 0.05$. $\mathrm{CAL}: \mathrm{CPL}=0.54: 0.51$. Supraclypeal area weakly shiny, with granular PP (20-30 $\mu \varnothing)$, somewhat coarse, dense, IS > 0.2 , reticulate. Clypeus nearly flat with granular PP $(20-40 \mu \varnothing)$, moderately dense, weakly reticulate above, IS smooth below. UOD: MOD: $\mathrm{LOD}=1.16: 1.37: 0.77$. Labrum with basal area, distal process absent; basal area about 3.6 times as wide as long, medially flat and not 
depressed in dorsal view; basal lateral depression and elevation absent. Mandible edentate. $\mathrm{EW}: \mathrm{GW}=0.65$ : 0.33; $\mathrm{SPL}=0.40-0.48, \mathrm{~F} 1 \mathrm{~L}: \mathrm{F} 2 \mathrm{~L}=0.18: 0.36$. Mesosoma: $\mathrm{HW}: \mathrm{MsW}: \mathrm{MtW}=$ 1.93: 2.15: 1.65. Mesoscutum with coarse reticulo-PP (20-40 $\mu \varnothing)$, all over, IS $>0.2$, or $0.2-1$, weakly reticulate and dull; mesoscutellum dull, distinctly convex, longitudinally depressed in the middle, with homogeneous PP with mesoscutum; MCL: MTL: PDL=0.49: 0.27: 0.39. Lateral slope of propodeal dorsum and propodeal side with transverse to oblique ridges; shield with irregular ridges. Basitibial plate absent. Metasoma: T1 medially to posteriorly with granular PP (10-20 $\mu \varnothing)$, moderately dense, smooth; T2 basally to medially with homogenous PP with T1, dense, posteriorly with sparse, basally and anteriorly weakly transverse striate, medially smooth; T3-4 similar to T2. S7-8 (Fig. 4 A) with short and round median process.

Male genitalia: Genitalia (Fig. 4 B-D). Gonobasal ventral arm ring-shaped, but not connected each other at upper ends in ventral view; median sulcus distinct in dorsal view. Gonocoxites in dorsal view, with outer margin gently outcurved, with inner margin hoeshaped anteriorly, and distinctly angulate medially in ventral view, with inner and outer margins relatively outcurved to paralleled. Gonostylus (Fig. 4D) ovate in ventral view, surface with sparse spots, and sparse short hairs outer marginally. Ventral retrose lobe absent. Penis valve slender, inner surface with short hairs, sparse, bluntly pointed at apex. Volsella round basally; lateral flange slightly convex and acute; lateral lobe not prominent.

Variation: Metasomal color in female presents three types (black, pale red, and intermediate types). Miyanaga et al. (1999) reported these color patterns of the metasomal terga in pre-hibernating females were clearly linked to their sizes; entirely black in the larger individuals, and pale-red color in the smaller ones.

Remarks: This species is characterized by having the following morphological features in the Japanese carinate-Evylaeus group: the head and mesosoma weakly blue-green reflections in female, the mesosoma dull blue-green in male; the mesoscutum medially with irregular sparse PP in female, rather dense PP in male; all tarsi pale yellowish in male; the inner hind tibial spur serrate in female.

Distribution: Japan (Hokkaido, Honshu, Shikoku, Kyushu, Yakushima Is.), China (Fukien), Korean Peninsula (north).

Flight records: Female: late March to early November. Male: late June to November.

Floral association: Polylectic: Erigeron annuus (Compositae); Kerria japonica var. albescens (Rosaceae); Achranthes japonica (Amaranthaceae); Brassica sp. (Cruciferae); Isodon infexus (Labiatae); Rhododendron sp. (Ericecae); Hydrangea paniculata (Saxifragaceae); Lespedeza bicolor var. japonica (Leguminosae); Polygonum cuspidatum (Polygonaceae); Angelica polyclada (Umbelliferae), etc.

Biology: See Sakagami \& Munakata (1966) and Miyanaga et al. (1999).

Specimens examined: We have examined 138 females and 68 males from the following localities in Japan; Hokkaido, Aomori, Miyagi, Fukushima, Niigata, Ibaraki, Tochigi, Tokyo, 
Kanagawa, Yamanashi, Fukui, Toyama, Ishikawa, Nagano, Gifu, Kyoto, Wakayama, Hyogo, Tottori, Tokushima, Ehime, Fukuoka, Nagasaki, Oita, Kumamoto, Miyazaki Prefs. Some of them are cited as follows: HOKKAIDO: 2 females, Ashoro, Tokachi, 1-2, 3-4. vii. 1960 (S. Nakano, ELKU). HONSHU: Kanagawa Pref.: 1 female, Miyagase, Kiyokawa-mura, 19. x. 2003 (R. Murao). Fukui Pref.: 7 females and 1 male, Kamikoike, Ono-shi, 14. v., 16. viii. 2002 (K. Mitai). SHIKOKU: Ehime Prefi: 3 males, Omogo, 7. ix. 1951 (Y. Hirashima, ELKU); 5 females, Wakayama, Omogo vill., 10. vi. 2004 (T. Sugimoto). KYUSHU: Fukuoka Pref.: 1 female, Ino-dam, Ino, Hisayama-town, Kasuya, 31. iii. 2003 (F. Kodoi). Oita Pref.: 2 females, Handa-kogen, Kokonoe-cho, Kusu, 12. v. 2003 (R. Murao). Kumamoto Pref.: 1 male, Choyo, Aso, 22. vi. 1996 (M. Yamada, ALKK); 1 female and 4 males, Asomachi, Aso, 8. xi., 20. xi. 2001 (A. Yamada \& M. Nomura, ALKK).

\section{Lasioglossum (Evylaeus) serratum (Bluithgen)}

(Figs. 3 C; 5 A-G)

Halictus serratus Blüthgen, 1926, Zool. Jb. Syst., 51: 623-625 [female, India?]. Lasioglossum (Evylaeus) serratum: Ebmer, 2002, Linzer biol. Beitr., 34 (2): 841.

\section{Redescription}

Female. BL 6.20-7.00 mm, WL 5.60-6.20 mm ( $\mathrm{n}=5)$.

Color: Body black except as follows: mandible with apical half reddish brown; flagellum beneath blackish brown to brown; tegula posteriorly and marginally brownish transparent; wings nearly transparent; veins and pterostigma blackish brown; tibial spur yellow; posterior margins of metasomal terga broadly brownish yellow transparent.

Pilosity: Generally dull whitish to pale yellowish brown. Head: Hairs on vertex 120-250 $\mu \mathrm{m}$, erect and poorly plumose, sparse; hairs on paraocular area, frons and supraclypeal area $100-200 \mu \mathrm{m}$, poorly plumose, sparse; hairs on clypeus 100-300 $\mu \mathrm{m}$, simple, sparse; hairs on genal area $120-400 \mu \mathrm{m}$, poorly plumose, moderately dense. Mesosoma: Lateral lobe of pronotum with tomental hairs; hairs on pronotal dorsum, poorly plumose, sparse; hairs on mesoscutum 100-120 $\mu \mathrm{m}$, semierect and poorly plumose, sparse; hairs on mesoscutellum 100$300 \mu \mathrm{m}$, marginally plumose, sparse; hairs on metanotum medially tomentum, dense, marginally plumose, sparse; tegula with poorly plumose hairs anteriorly; hairs on mesepisternum and metepisternum 200-400 $\mu \mathrm{m}$, plumose, moderately dense; hairs on propodeal side plumose, sparse; hairs on propodeal shield plumose, sparse. Metasoma: Hairs pale yellowish brown; anterior and lateral hairs on $\mathrm{T} 1100-150 \mu \mathrm{m}$, erect and poorly plumose, sparse; hairs on $\mathrm{T} 2$, laterally poorly plumose, sparse, disc simple and short, sparse; hairs on T3-4 simple and short all over, laterally poorly plumose, sparse; basal hair bands of T2-4 present with whitish tomentum; hairs on metasomal sterna $300-600 \mu \mathrm{m}$, poorly plumose, moderately dense. 


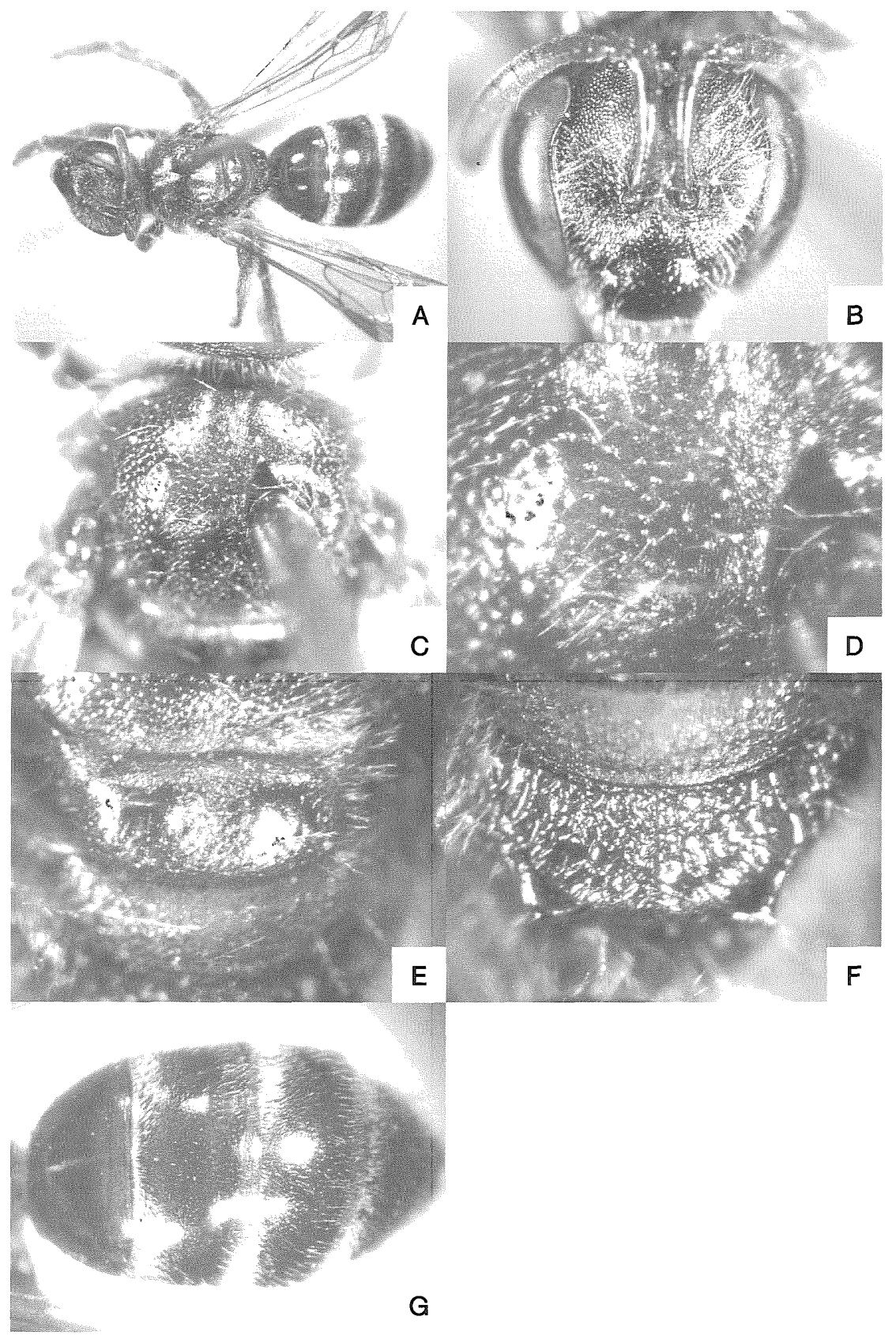

Fig. 5. Lasioglossum (Evylaeus) serratum (Blüthgen), female. A: dorsal view; B: face; C: mesoscutum; D: sculpture of mesoscutum; E: mesoscutellum; F: propodeal dorsum; G: metasomal terga. 
Structure: Head: HW: $\mathrm{HL}=1.82: 1.66$. Vertex gently outcurved in frontal view, behind ocelli distinctly striae; IOD: $\mathrm{OOD}: \mathrm{OCD}=0.32: 0.30: 0.05$. Ocellocular and paraocullar area weakly shiny, with reticulo-punctures $(20-30 \mu \emptyset)$; frons nearly flat, dull, with homogeneous $\mathrm{PP}$, similar to ocellocular and paraocular areas. $\mathrm{CAL}: \mathrm{CPL}=0.31: 0.38$. Supraclypeal area shiny, slightly convex in lateral view, with granular PP $(20 \mu \varnothing)$, sparse, IS $=1-4$, weakly reticulate. Clypeus nearly flat, with larger shallow PP (20-40 $\mu \varnothing)$, sparse, weakly reticulate above, smooth and shiny below. UOD: MOD: LOD $=1.07: 1.33: 1.04$. Labrum with basal area and distal process; basal area about 2.5 times as wide as long, apically with slightly depressed in dorsal view; basal lateral depression absent; basal elevation well developed, narrow apically; distal process as wide as basal elevation in dorsal view; distal lateral projection present, with spoon-shaped in dorsal view; distal keel narrow, apically pointed in dorsal view; labral fimbria all acutely pointed at apex. Mandible bidentate. Hypostomal carina moderately developed; anterior angle of hypostomal carina obtuse. Occiput not carinate. $\mathrm{EW}$ : $\mathrm{GW}=0.44$ : 0.36 ; genal area shorter than eye, surface with oblique striae; SPL $=0.80-0.88, F 1 L$ : F2L $=$ 0.11: 0.10. Mesosoma: $\mathrm{HW}: \mathrm{MsW}: \mathrm{MtW}=1.82: 1.96: 1.87$. Pronotum with dorsolateral angle obtuse. Mesoscutum shiny, with granular PP (20-30 $\mu$ ø), sparse all over, IS=1-5, anteriorly weakly reticulate, medially to posteriorly smooth; mesoscutellum medially weakly depressed, marginally and longitudinally with granular PP (20-30 $\mu \varnothing)$, dense, IS smooth and shiny; metanotum rugulose. Mesepisternum coarsely striate all over; metepisternum above half with homogenous striae with mesepisternum; MCL: MTL: PDL=0.42: 0.29: 0.41. Propodeal dorsum gently inclined; dorsal propodeal surface with distinct ridges all over, medially with irregularly winding ridges, laterally with longitudinal ridges attain to lateral slope; transverse carina weak (somewhat indistinct); lateral carina developed, parallel-sided; oblique carina developed, but not connected each other at upper ends; propodeal side weakly rugulose; shield distinctly reticulate, median with longitudinal concave. Tegula smooth and weakly shiny. Hind legs with basitibial plate ovate, pointed apically; inner hind tibial spur serrate. Metasoma: metasomal terga weakly shiny. T1 medially with ill-defined PP $(<10 \mu \varnothing)$, sparse, surface with smooth; T2 basally to medially with fine PP $(<10 \mu \varnothing)$, moderately dense, sparse posteriorly, IS basally weakly transverse striae, medially to posteriorly smooth; T3 with illdefined PP $(<10 \mu \varnothing)$, sparse, IS basally and posteriorly weakly striae, medially smooth; T4 with homogenous PP with T3, IS weakly striae all over. Metasomal sterna disitnctly reticulate.

Male. Unknown.

Remarks: This species resembles Lasioglossum apristum (Vachal) in having the head and mesosoma with weak blue-green reflections, the shape of head, labrum and inner hind tibial spur, the surface of mesoscutum and propodeum, but can be distinguished from it by the distal process of labrum more developed, the basal area of labrum gently outcurved at anterior margin (more strongly outcurved in apristum), the surface of T1 with ill-defined PP, and the 
surfece of T2 smooth posteriorly.

Distribution: Nepal, West-Bhutan.

Flight records: Female: May to July.

Floral association: Not available.

Biology: Unknown.

Specimens examined: [NEPAL]: 4 females, Namche, Bazar, 8. vii. 1968 (T. Matsumura, SCMH) ; 1 female, Karte, Salwng (1500-2900m), 12. vii. 1968 (T. Matsumura, SCMH).

\section{Acknowledgements}

We are especially indebted to the late Prof. Emeritus S. F. Sakagami (Hokkaido University) whose collection of Evylaeus was most useful in this study. Our sincere appreciation is extended to the following persons and institutions for loan of specimens: Mr. M. Iwata (ALKK), Mr. K. Mitai (ELKU), and Mr. T. Sugimoto (ELKU).

\section{References}

Blüthgen, P., 1926. Beiträge zur Kenntnis der indo-malayischen Halictus- und ThrincostomaArten. Zool. Jahrb., Abt. f. Syst., 51: 375-698.

Ebmer, A. W., 1978. Die Bienen der Gattungen Halictus Latr., Lasioglossum Curt. und Dufourea Lep. (Hymenoptera, Halictidae) aus Korea. Annls. Hist. Natn. Hung., 70: 307319.

Ebmer, A. W., 1995. Asiatische Halictidae, 3. Die Artengruppe der Lasioglossum carinateEvylaeus (Insecta: Hymenoptera: Apoidea: Halictidae: Halictinae). Linzer Biol. Beitr., 27: 525-652.

Ebmer, A. W., 1997. Asiatische Halictidae, 6. Lasioglossum carinaless-Evylaeus: Ergänzungen $\mathrm{zu}$ den Artengruppe von L. nitidiusculum und L. punctatissmum s.l., sowie die Artengruppe des L. marginellum (Insecta: Hymenoptera: Apoidea: Halictidae: Halictinae). Linzer Biol. Beitr., 29: 921-982.

Ebmer, A. W., 2002. Asiatische Halictidae, 10. Neue Halictidae aus China sowie diagnostische Neubeschreibungen der von Fan \& Ebmer 1992 beschriebenen Lasioglossum-Arten (Insecta: Hymenoptera: Apoidea: Halictidae: Halictinae). Linzer Biol. Beitr., 34: 819-934.

Eickwort, G. C., 1969. A comparative morphological study and generic revision of the Augochlorine bees (Hymenoptera: Halictidae). Univ. Kansas Sci. Bull., 48: 325-524.

Hirashima, Y., 1957. A tentative catalogue of the genus Halictus Latreille of Japan, and her adjacent territories (Hymenoptera, Halictidae). Sci. Bull. Fac. Agr., Kyuhshu Univ., 16 (1) : $1-30$. 
Ikudome, S., 1999. Family Halictidae, In Yamane, S., S. Ikudome \& M. Terayama. Identification Guide to the Aculeata of the Nansei Islands, Japan. Hokkaido University Press, Sapporo.

Matsumura, S., 1912. Thousand Insects of Japan. Supplement. IV. Keiseisha, Tokyo.

Matsumura, S., 1930. The Illustrated Thousand Insects of Japan. II. Kataeshoin, Tokyo.

Matsumura, S., 1931. 6000 Illustrated Insects of Japan-Empire. Kataeshoin, Tokyo.

Matsumura, S., 1932. Illustrated Common Insects of Japan. IV. Shunyodo.

Michener, C. D., 2000. The Bee of the World. The John Hopkins University Press, Baltimore \& London.

Miyanaga, R., Y. Maeta and S. F. Sakagami, 1999. Geographical variation of sociality and size-linked color patterns in Lasioglossum (Evylaeus) apristum (Vachal) in Japan (Hymenoptera, Halictidae). Insectes Soc., 46: 224-232.

Sakagami, S. F. and M. Munakata, 1966. Bionomics of a Japanese halictine bee, Lasioglossum pallidulum (Hymenoptera: Apoidea). J. Kansas Ent. Soc., 39: 370-379.

Sakagami, S. F. and O. Tadauchi, 1995. Taxonomic studies on the halictine bees of Lasioglossum (Evylaeus) lucidulum subgroup in Japan with comparative notes on some Palaearctic species (Hymenoptera, Apoidea). Esakia, (35): 141- 176.

Vacha1, J., 1903. Hyménoptères rapportés du Japon par M. Harmand, Mellifères. Bull. Mus. Hist. Nat., 1903: 129-132. 